\title{
BERMUHAMMADIYAH MELALUI SPIRITUAL AMAL SALEH FILANTROPI CILIK LAZISMU: LITERATUR FUNGSI BAHASA
}

\author{
Marwanto \\ IAIN Salatiga \\ E-Mail: marwanto@iainsalatiga.co.id
}

\begin{abstract}
Abstrak: Filantropi cilik Sekolah Dasar Muhammadiyah Plus Salatiga mengajak untuk terus mengajarkan dan mengetuk hati siswa-siswinya agar mau beribadah sosial dan menyadarkan akan arti pentingnya membantu sesama. Pengambilan segmen cilik dikarenakan segmen anak-anak yang menjadi tujuan. Filantropi Cilik mengambil segmen siswa sekolah Amal Usaha Muhammadiyah yaitu Sekolah Dasar Muhammadiyah Plus Salatiga. Penelitian ini merupakan penelitian deskriptif kuantitatif. Subjek dalam penelitian ini adalah siswa Sekolah Dasar Muhammadiyah Plus Salatiga. Metode yang digunakan dalam penelitian ini yaitu menggunakan metode wawancara siswal siswi, guru, dan pengurus Lazismu Salatiga dengan menggunakan teknik simak dan catat. Sementara data pada penelitian ini berupa hasil wawancara. Fokus penelitian ini pada bagaimana Bermuhammadiyah melalui Spiritual Amal Saleh Filantropi Cilik Lazismu dengan bertumpu pada literatur fungsi bahasa.
\end{abstract}

Kata Kunci: filantropi cilik, sekolah dasar muhammadiyah, lazismu

\section{PENDAHULUAN}

Muhammadiyah organisasi besar di Indonesia. Muhammadiyah mempunyai arti pengikut nabi Muhammad, dari kata Muhammad dan iyah (pengikut). Pemilihan nama Muhammadiyah bukan asal-asalan saja akan tetapi itu mengandung makna yang mendalam bagi sejarah perkembangan Muhammadiyah, terutama bagi masyarakat umum, nama itu merupakan sesuatu yang asing, namun masyarakat malah merasa terpancing ingin tahu sehingga dari situlah Kyai Dahlan memberikan pesan dan penjelasan yang seluas-luasnya tentang agama Islam sesuai yang diajarkan nabi Muhammad SAW

Pergerakan Muhammadiyah tidak pernah lepas dari pendidikan dan amal saleh. Kelahiran Muhammadiyah melekat dengan pemikiran, sikap, dan langkah pendirinya Kyai Dahlan yang ingin mengembalikan Islam sesuai al Quran dan Sunnah Nabi. Muhammadiyah bericita-cita membebaskan umat Islam dari keterbelakangan dan membangun kehidupan yang berkemajuan. Surat al Maun merupakan contoh pembaharu Islam yang dibawa oleh Dahlan dalam rangka membebaskan masyarakat dari keterbelakangan tersebut. Dahlan tidak hanya berorientasi pada ibadah semata, namun justru peduli pada masalah konkret yang dihadapi manusia kala itu. Al Maun dibedah menjadi sesuatu yang nyata, bukan hanya sampai pada tarap baca dan hafalan, namun sampai ke amaliyah yang sesungguhnya.

Pemikiran Dahlan tentang al Maun menjadikan landasan melihat realita sosial dan pentingnya aktifitas sosial. Artinya amalan ibadah tidak akan ada artinya apabila tidak disertai dengan aktifitas amal sosial. Al Maun memberikan solusi bagaimana manusia harus melihat jelas realita yang sesungguhnya tentang kepedulian terhadap sesama dalam hal ini anak yatim dan menjadi dermawan bagi yang kuasa dalam harta. Al Maun 
juga menjadi landasan bagi gerakan sosial Muhammadiyah dan sekaligus memberikan inspirasi agar manusia sadar secara kolektif dan peka terhadap kemiskinan.

Al Maun menimbulkan pemikiran bahwa ada banyak ladang dakwah bagi Muhammadiyah yang harus diselesaikan. Potret kemiskinan pada waktu itu menjadi hiasan dan tidak ada orang yang peduli. Dahlan mampu membaca potret kemiskinan pada waktu itu. Bersama para muridnya melakukan aksi nyata membantu mereka dan menterjemahkan al Maun ke dalam kehidupan nyata. Al Maun diterjemahkan dan bukan hanya sekedar bacaan sehingga lahirlah panti asuhan. Pada zaman modern ini Muhammadiyah mendirikan Lazismu sebagai tempat bagi para dermawan berbagi terhadap sesama.

Pemikiran di atas terus menjadi perenungan bagi generasi baru untuk dapat melahirkan pemikiran baru bagaimana upaya melanjutkan dan terus berkemajuan dalam memikirkan sesama. Melalui filosofi filantropi cilik Sekolah Dasar Muhammadiyah Plus Salatiga terus mengajarkan dan mengetuk hati siswa-siswinya agar mau beribadah sosial dan menyadarkan akan arti pentingnya membantu sesama. Kaleng filantropi cilik adalah sebuat tempat berbentuk tabung yang pada posisi atas tengah diberikan lubang untuk memasukkan uang kertas atau koin. Pada sisi-sisinya terdapat tulisan filantropi cilik dan ajakan beramal saleh.

Filntropi sendiri berasal dari kata Philanthopy, philos bermakna cinta dan anthropos bermakna manusia. Sementara filantropi sendiri merupakan praktik giving, service, association dalam membantu pihak lain atau dapat dikatakan tindakan sukarela untuk membantu orang lain. ${ }^{1}$ Filantropi juga

1 Zaenal Abidin, 'Manifestasi Dan Latensi Lembaga Filantropi Islam Dalam Praktik Pemberdayaan diartikan sebagai tindakan sukarela untuk kepentingan publik. ${ }^{2}$ Filantropi adalah sebuah kegiatan dengan maksud memberi bantuan, baik uang, barang, maupun pekerjaan yang bertujuan untuk meningkatkan kehidupan dan kesejahteraan kaum miskin. ${ }^{3}$ Filantropi dapat dikatakan sebagai suatu tindakan yang disengaja untuk membantu dan meringankan manusia. Artinya minimal filantropi mampu orang yang diberi bantuan mampu bertahan hidup atau minimal bisa meringankan beban masalah kehidupan manusia selama ini.

Sekarang ini, filantropi dapat diwujudkan dalam bentuk bantuan sosial, berupa zakat, infak, sadaqah, dan wakaf. ${ }^{4}$ Lazismu Salatiga sendiri bantuan tersebut didistribusikan melalui bantuan pendidikan (beasiswa), ekonomi (bantuan modal dan pelatihan kewirausahaan), social dan kemanusiaan (bedah rumah, santunan yatim piatu/ dhuafa, dan bantuan beras), dan keagamaan/ dakwah (santunan mubaligh, fisabilillah, kado Ramadhan, dan qurbanmu).

Spiritualitas berasal dari kata spirit yang berarti jiwa. Spirit dalam Kamus Besar Bahasa Indonesia berarti semangat atau jiwa. Spiritualitas adalah proses pencarian makna, tujuan, moralitas, kesejahteraan dalam hubungan dengan diri sendiri, orang lain, dan realitas yang hakiki ${ }^{5}$. Spiritualitas bisa dikatakan sebagai pencarian rohani secara individu dalam upaya pendekatan diri terhadap Tuhan. Dyson mengemukakan tiga faktor

Masyarakat: Suatu Studi Di Rumah Zakat Kota Malang', Jurnal Studi Masyarakat Islam, 15 (2012), 197-214.

2 Chusnan Jusuf, 'Filantropi Modern Untuk Pembangunan Sosial', Jurnal Penelitian Dan Pengembangan Kesejahteraan Sosial, 12.1 (2007), 74-84.

3 I. H. Tamin, 'Peran Filantropi Dalam Pengentasan Kemiskinan Di Dalam Komunitas Lokal.', Jurnal Sosiologi Islam, 1.1 (2011), 36.

4 Okta Nurul Hidayati, 'Filantropi Dakwah Dan Kaum Minoritas Di Indonesia', Academika, 1.2 (2017).

$5 \quad$ Yulmaida Amir and Diah Rini Lesmawati, 'Religiusitas Dan Spiritualitas: Konsep Yang Sama Atau Berbeda?', Jurnal Ilmiah Penelitian Psikologi, 2.2 (2016), 67-73. 
yang berhubungan dengan spiritualitas yaitu diri sendiri,sesama, Tuhan, dan lingkungan. ${ }^{6}$

Amal saleh adalah perbuatan atau aktivitas yang baik. Amal adalah perbuatan yang dikerjakan dengan niat tertentu dan saleh artinya baik atau dapat diartikan sebagai perbuatan yang baik dan bermuara pada kebaikan pula bagi kehidupan manusia. ${ }^{7}$ Sementara amal saleh ialah menjalankan perintah Allah dan menjauhi larangannya. ${ }^{8}$ Amal saleh adalah perbuatan yang membawa kemaslahatanbagisesama, yang dilakukan sesuai dengan petunjuk Allah dan contoh RasulNya. ${ }^{9}$ Amal saleh dapat dikatakan sebagai perbuatan baik yang dilakukan oleh manusia dalam kehidupannya bersama manusia,makhluk, dan lingkungan.

Pengambilan segmen cilik dikarenakan segmen anak-anak yang menjadi tujuan. Filantropi Cilik mengambil segmen siswa sekolah Amal Usaha Muhammadiyah yaitu Sekolah Dasar Muhammadiyah Plus Salatiga. Sementara Lazismu adalah Lembaga Amil, Zakat, Infaq, dan Sodaqoh dibawah persyarikatan Muhammadiyah Kota Salatiga.

Penelitian ini menggunakan literatur fungsi bahasa yaitu sebagai media komunikasi, sebagai alat mengungkapkan perasaan atau ekspresi diri, sebagai adaptasi dan integrasi sosial, dan sebagai kontrol sosial. Sebagai alat komunikasi bahasa menekankan pada komunikasi antara anggota masyarakat

6 Koopsen. Young, Spiritual, Kesehatan, Dan Penyembuhan (Medan: Bina Media Perintis, 2007).

7 Yusran, 'Amal Saleh: Doktrin Teologi Dan Sikap Sosial', Al-Adyan, 1.Desember 2015 (2004).

8 Dindin Moh Saepudin and others, 'Iman Dan Amal Saleh Dalam Al Quran (Studi Kajian Sematik)', Al Bayan: Jurnal Studi Al Quran Dan Tafsir, 1.Juni (2017), 10-20.

9 Moch. Hasan Sya'roni, 'Implementasi Kegiatan Amal Saleh Dalam Peningkatan Kecerdasan Spiritual: Studi Kasus Di Pondok Pesantren Al Urwatul Wutsqo Bulurejo Diwek Jombang', Didaktika Religi, 2.1 (2014), 65-90 sebaiknya sudah mempunyai tujuan atau gagasan yang akan disampaikan. Bahasa mampu menghantarkan manusia untuk senantiasa berkomunikasi satu dengan yang lain. Beradaptasi dalam memilih bahasa saat berkomunikasi dengan orang lain, sekaligus bagaimana menyampaikan gagasan kita dengan baik dan benar agar mampu diterima dengan baik pula oleh orang lain sebagaimana fungsi bahasa tersebut.

Beberapa penelitian yang berhubungan dengan filantropi sudah banyak dilakukan, namun yang membahas secara khusus Bermuhammadiyah melalui spiritualitas amal saleh filantropi cilik belum ada yang meneliti sebelumnya. Berikut beberapa penelitian tersebut. Penelitian Linge (2015) dalam judulnya Filantropi Islam sebagai Instrumen Keadilan Ekonomi. ${ }^{10}$ Linge menggunakan efektifitas filantropi dalam upaya mengurangi kesenjangan sosial. Berbeda lagi dengan Gerakan Filantropi Islam di Amerika oleh Hasyim (2018). Hasyim ingin mengetahui perkembangan filantropi Islam di Amerikaa Serikat. ${ }^{11}$ Sementara Makhrus dan Utami (2015) dengan judul Peran Filantropi Islam dalam Pemberdayaan Masyarakat di Kabupaten Banyumas. ${ }^{12}$ Peneltian lembaga filantropi Islam dalam mengoptimalkan pemberdayaan masyarakat di Kabupaten Banyumas dan untuk mengetahui realisasi program pemberdayaan masyarakat yang sudah dilaksanakan lembaga filantropi Islam di Kabupaten Banyumas.

Berdasarkan beberapa penelitian di atas tidak ada satupun yang sama

10 Abdiyansyah Linge, 'Filantropi Islam Sebagai Instrumen Keadilan Ekonomi', Jurnal Perspektif Ekonomi Darussalam, 1.September (2015), 154-71.

11 Fuad Hasyim, 'Gerakan Filantropi Islam Di Amerika', Jurnal Studi Al-Qur'an, 14.1 (2018), 16-31.

12 Makhrus Ahmadi and Restu Frida Utami, 'Peran Filantropi Islam Dalam Pemberdayaan Masyarakat Di Kabupaten Banyumas', in Seminar Nasional HasilHasil Penelitian Dan Pengabdian LPPM Universitas Muhammadiyah Purwokerto, 2017. 
walaupun kesemuanya berbicara tentang filantropi. Penelitian ini dilakukan di Sekolah Dasar Muhammadiyah Plus Salatiga. Subjek penelitian adalah siswa SD Muhammadiyah Plus Salatiga. Fokus penelitian ini bagaimana Bermuhammadiyah melalui Spiritual Amal Saleh Filantropi Cilik Lazismu dengan menggunakan Literatur Fungsi Bahasa.

\section{METODE}

Penelitian ini merupakan penelitian deskriptif kuantitatif. Subjek dalam penelitian ini adalah siswa Sekolah Dasar Muhammadiyah Plus Salatiga. Metode yang digunakan dalam penelitian ini yaitu menggunakan metode wawancara siswa/ siswi, guru, dan pengurus Lazismu Salatiga dengan menggunakan teknik simak dan catat. Sementara data pada penelitian ini berupa hasil wawancara.

\section{HASIL DAN PEMBAHASAN}

Sekolah Dasar Muhammadiyah Plus Salatiga merupakan salah satu Sekolah Dasar unggulan dan diunggulkan di kota Salatiga. Atensi masyarakat untuk menyekolahkan putra-putrinya terbukti sudah menitipkan akta kelahiran putraputrinya di SD Muhammadiyah Plus Salatiga satu tahun sebelumnya, agar mendapatkan kuota kelas. Tercatat ada seribu siswa, dari kelas I sampai dengan kelas VI. Guru sebanyak 53 orang terdiri atas guru laki-laki 12 orang dan guru perempuan sebanyak 41 orang). Semboyan "Anak Cerdas Berakhlak Mulia" dan visi sebagai pusat keunggulan dibidang iman dan taqwa (IMTAQ) dan ilmu pengetahuan dan teknologi (IPTEK) yang berkarakter kebangsaan dan peduli lingkungan serta dengan misi, 1) menumbuhkan sikap kemandirian beribadah, 2) membentuk pribadi sopan dalam bersikap, santun dalam berucap, dan berempati, 3) menghargai dan membentuk peserta didik, 4) mengembangkan budaya lokal dan kreatifitas peserta didik, 5) menciptakan, menumbuhkan budaya bersih dan sehat serta memelihara lingkungan hidup, 6) menumbuhkan belajar mandiri, 7) mengembangkan budaya disiplin dan berprestasi, 8) menggali, menumbuhkan, dan melejitkan prestasi potensi peserta didik, 9) memberikan bekal dasar ketrampilan TIK dan bahasa asing, dan 10) meraih posisi sekolah bertaraf internasional.

SD Muhammadiyah Plus Salatiga dalam menterjemahkan semboyan dan misi sekolah bekerjasama dengan Lazismu Salatiga membagikan kaleng Filantropi Cilik. Tujuan daripada kegiatan ini adalah sarana untuk mewujudkan kepedulian terhadap sesama. Selain belajar untuk peduli terhadap sesama, siswa juga diharapkan mampu menaplikasikan hasil pembelajaran yang sudah dilakukan selama ini di sekolah.

Program filantropi cilik bertujuan untuk menanamkan jiwa cinta bersedekah, mengajarkan sejak dini agar terbiasa beramal, berderma, serta peduli terhadap sesama kepada siswa-siswi SD Muhammadiyah Plus Salatiga. Sejak dini dijarkan untuk senantiasa ikhlas beramal saleh. Filantropi cilik merupakan sebuah gerakan Lazismu bekerjasama dengan SD Muhammadiyah Salatiga dengan cara membagikan kaleng berbentuk tabung kepada para siswa untuk di isi dengan uang di rumah masing-masing. Kegiatan ini sukarela dan tanpa paksaan dengan melalui sosialisasi kepada siswa terlebih dahulu atas manfaat dan tujuan filantropi cilik tersebut.

Dana bantuan yang sudah terkumpul akan disalurkan melalui Lazismu Salatiga. Program daripada Lazismu sendiri yaitu 1) Pendidikan meliputi beasiswa yatim dan dhuafa, beasiswa sarjana, bantuan school kids, dan beasiswa guru honorere, 2) Ekonomi meliputi bantuan modal usaha mikro dan pelatihan kewirausahaan, 3) 
Sosial dan Kemanusiaan meliputi bedah rumah dhuafa, santunan yatim dan dhuafa, dan bantuan beras bagi keluarga miskin, dan 4) Keagamaan atau Dakwah meliputi pembinaan muzaki, munfiq, dan mutashodiq, santunan mubaligh dan mubalighot, bantuan kegiatan (fisabilillah), kado ramadan, dan Qurbanmu. ${ }^{13}$

Lazismu sendiri selama ini mendapatkan zakat, infaq, sedekah, dan wakaf dari para donatur atau para dermawan yang menyumbangkan rezekinya melalui Lazismu. Ratarata perolehan ZIS (Zakat, Infaq, dan Sodaqoh) setiap bulan mencapai 20 juta. Program Lazismu jemput bola dan kirim melalui rekening meringankan sekaligus membuat senang para donatur yang ingin beribadah dengan cara beramal melalui Lazismu Kota Salatiga. Selama ini para donatur merasa kesulitan mencari tempat untuk menyalurkan ZIS-nya.

Berikut hasil wawancara dengan subjek yang berhubungan langsung dengan bermuhammadiyah melalui Spiritualitas Amal Saleh Filantropi Cilik lazismu.

Prof. Dr. Muh. Zuhri, M.A (Ketua Dewan Syariah Lazismu)

Islam mengajarkan hidup itu tolong menolong. Bahagia itu bukan karena dengan harta yang melimpah, tetapi mengantarkan dan membantu orang lain menjadi bahagia dengan apa yang kita miliki. Maka benarlah kata orang "life is all about contibution".

\section{Marijo, M.Pd (Direktur Lazismu Salatiga)}

Lazismu atau Lembaga Zakat Infaq dan Shadaqah Muhammadiyah adalah lembaga zakat tingkat nasional yang berkhidmat dalam pemberdayaan

13 Muthoifin and Nuha, 'The Optimization of Local Autonomy Politic for Nation Progress and Synergetic on Islamic Perspective', in The 4th University Research Coloquium 2016, 2016, pp. 72-79<https:// publikasiilmiah.ums.ac.id/xmlui/handle/11617/7679>. masyarakat. Tujuan kami yaitu membangkitkan motivasi untuk membantu sesame, meningkatkan kualitas dakwah social, dan melakukan aksi social yang tepat. Kebanggaan bagi kami pengelola dan petugas Lazismu adalah bisa memberikan tempat dan memediasi bagi para dermawan, para muzaki dalam menyalurkan zakat, infaq, dan shadaqahnya kepada yang berhak. Sementara melalui kaleng filantropi ini, kami mengajak anda semua untuk peduli terhadap sesame, khususnya filantropi cilik Lazismu ini kami tujukan kepada SD dan SMP Muhammadiyah Plus Salatiga. Kami berharap siswa-siswi bisa belajar sejak dini tentang bagaimana rasanya dapat membantu orang lain melalui uang saku yang mereka sisihkan setiap harinya.

Sutomo (Direktur SD Muhammadiyah Plus Salatiga)

Dia menyampaikan agar anak-anak mulai dari kecil belajar beramal saleh. Kaleng Filantropi ini membantu siswasiswi SD Muhammadiyah Plus Salatiga untuk senantiasa belajar menyisihkan uang jajannya dan semangat berbagi kepada yang membutuhkan. Semangat belajar beramal saleh harus dipupuk dari usia kecil sehingga ketika besar sudah menjadi kebiasaan. Selain itu belajar beramal juga harus mempunyai tempat yang tepat. Alhamdulillah Muhammadiyah mempunyai Lazismu. Tempat yang tepat bagi anak-anak untuk menyalurkan amal salehnya.

\section{AinulHuri, M.Pd(KepalaSDMuhammadiyah} Plus Salatiga)

Sangat bangga kami mempunyai siswa-siswi yang senantiasa mau berbagi dengan saudaranya yang sangat membutuhkan. Semoga ini bisa terus dikembangkan di sekolah ini dan semakin banyak siswa-siswi yang mau berpartisipasi, bahkan kalau bisa semua tanpa harus diminta. Filantropi cilik ini 
bagi kami merupakan sesuatu yang tepat karena sebagai pembelajaran sejak dini bagi anak-anak agar suatu kelak ketika dewasa sudah menjadi kebiasaan tanpa paksaan.

\section{A.M.F. El-Firdausy (Siswa SD} Muhammadiyah Plus Salatiga Kelas I)

Kaleng cilik sangat menarik. Saya ambil satu dan setiap hari saya isi, kemudian kalau sudah penuh saya kembalikan ke sekolah. Saya ambil lagi yang kosong untuk bawa pulang dan di isi lagi. Ayah dan Ibu juga mengingatkan setiap saat untuk mengisi kaleng tersebut dan jangan lupa. Katanya buat belajar menyisihkan uang saku untuk membantu temanku yang membutuhkan.

\section{Faqih Kamal Rais (Siswa SD Muhammadiyah} Plus Salatiga Kelas II)

Ketika diperlihatkan kaleng filantropi Lazismu bentuknya menarik. Awalnya tertarik dari bentuknya. Kemudian saya ambil satu dan saya laporkan orang tua. Orang tua saya langsung faham buat apa arti kaleng filantropi tersebut. Saya selalu diingatkan untuk mengisi setiap hari, walaupun hanya 1000 atau 2000 rupiah.

\section{Zara Naila Az-Zahra (Siswa SD} Muhammadiyah Plus Salatiga Kelas III)

Sejak kecil saya sudah diajarkan orang tua untuk membantu orag lain. Ketika saya pulang membawa kaleng filantropi ini. Orang tuaku bersemangat dan menasehati untuk selalu mengisinya. Alhamdulillah ada tempat untuk berbagi dengan teman-teman yang membutuhkan bantuan dan ada yang membantu menyalurkannya.

Muhammad Zidan Almas D (Siswa SD Muhammadiyah Plus Salatiga Kelas IV)

Selalu memasukkan uang dari pemberian orangtuanya di kaleng Filantropi, walaupun hanya seribu atau duaribu rupiah setiap harinya. Kemudian kalau sudah penuh dikembalikan kepada guru kelasnya dan meminta kembali kaleng Filantropi yang baru untuk diisi kembali. Ia merasa senang tanpa harus dipaksa dan terpaksa.

Almira Kirana (Siswa SD Muhammadiyah Plus Salatiga Kelas V)

Kaleng cilik Lazismu bisa untuk belajar sejak kecil untuk berbagi dengan teman-teman. Semoga ini bisa ringan dalam saya berbagi dengan yang lain. Semoga saya bisa terus mengikutinya sampai nanti selesai dan lulus dari sekolah ini.

Khoiru Nizam (Siswa SD Muhammadiyah Plus Salatiga Kelas VI)

Alhamdulillah bisa menjadi bagian dari filantropi cilik ini. Saya bersama teman-teman mempromosikan di sekolah saya akan manfaat dan tujuan dari filantropi ini. Alhamdulillah banyak yang berminat dan tertarik. Saya dan teman-teman berharap semoga ini terus dilakukan tanpa henti karena manfaatnya sangat terbukti.

I'anatul Khasanah (Guru Kelas I SD Muhammadiyah Plus Salatiga)

Awalnya siswa bertanya-tanya tentang kaleng filantropi Lazismu, setelah kami jelaskan tentang manfaatnya mereka senang dan meminta kaleng filantropi tersebut, bahkan ada yang meminta dua.

\section{Riyani Maunah (Guru Kelas II SD Muhammadiyah Plus Salatiga)}

Siswa kelas II sangat senang dengan adanya kaleng filantropi ini. Ini sebagai latihan dan terus melaksanakan amalan yang baik guna membantu orang lain. Bahkan putra-putri saya pun, keduanya juga melakukannya. Semua membawa kaleng filantropi ke rumah. 
Rifa Asqowi (Guru SD kelas VI SD Muhammadiyah Plus Salatiga)

Saya rasa bagi kelas VI, kelas V, dan kelas IV sudah memahami arti dan manfaat dari kaleng filantropi ini. Mereka sudah belajar dan memahami sejak mereka kelas III dulu, saat pertama kali dicanangkan dan disosialisasikan.

Nurma (sie pembuka kaleng filantropi $S D$ Muhammadiyah Plus)

Dia menyampaikan bahwa perolehan setiap kaleng 30-100, rata-rata setiap kelas 20 kaleng dari jumlah semua siswa yang beramal saleh melalui kaleng filantropi. Perhitungan itu meliputi kelas I, II, dan III sebanyak VI kelas, kelas IV sejumlah V kelas, sementara kelas V dan IV sebanyak 4 kelas.

Bidah Sariyati (Petugas Pelaporan Lazismu). Alhamdulillah melalui kaleng filantropi ini dari siswa dapat terkumpul rata-rata 9 juta setiap bulannya.

Berdasarkan hasil wawancara di atas dapat disimpulkan bahwa terdapat atensi dan dukungan yang baik terhadap pelaksanaan filantropi cilik Lazismu di Sekolah Dasar muhammadiyah Salatiga. Indikasinya adalah semua mendukung dan menyambut baik kegiatan tersebut. Lazismu mampu mengsosialisasikan dan menjadi patner yang baik. Direktur, kepala sekolah dan para guru bersinergi mendukung dan memberikan suport kepada siswa terhadap filantropi cilik Lazismu ini. Lazismu menjadi tempat yang tepat bagi siswa-siswi SD Muhammadiyah Plus Salatiga belajar berderma atau membantu sesama, membantu teman-temannya yang sangat membutuhkan dengan cara menyisihkan uang jajannya setiap hari. Sementara siswa juga menyambut baik pelaksanaan filantropi ini, bahkan aksi dan kepedulian mereka ini mendapat dukungan pula dari orang tua mereka sendiri.
Hal ini sejalan dengan penelitian yang dilakukan oleh Linge $(2015)^{14}$ dan Makhrus dan Utami (2015). ${ }^{15}$ Linge menggunakan efektifitas filantropi dalam upaya mengurangi kesenjangan sosial. Penelitian ini juga berjalan efektif pada proses pengumpulannya dan manfaatnya juga sesuai dengan sasaran yakni membantu sesama yang membutuhkan atau sesuai program Lazismu. Selain itu penelitian ini juga berhasil optimal dalam menjaring para muzaki cilik dan optimal dalam pentasarupannya bagi mereka yang membutuhkan atau dapat dikatakan sesuai penelitian yang dilakukan oleh Makhrus dan Utami. Artinya filantropi cilik Lazismu SD Muhammadiyah Plus Salatiga dalam pengumpulannya berjalan dengan optimal atau sesuai dengan target. Banyak muzaki-muzaki cilik yang berminat dan mau mengikuti program ini. Sementara pentasarupannya juga efektif sesuai dengan kemanfaatannya bagi sesama.

Bermuhammadiyah melalui Spiritualitas Amal Saleh Filantropi Cilik lazismu menurut Dyson berhubungan dengan tiga faktor spiritualitas yaitu diri sendiri,sesama, Tuhan, dan lingkungan. ${ }^{16}$ Keempat faktor tersebut diuraikan sebagai berikut.

\section{Diri sendiri.}

Bidang akademik Guru memberikan materi pembelajaran dan mengajarkan keteladanan. Keteladanan yang ditanamkan guru di Sekolah Dasar Muhammadiyah Plus Salatiga adalah keteladanan yang mencontoh Rasulullah saw dalam bermasyarakat, sosial, maupun bernegara yang menanamkan karakter religius dan nasionalis.

Karakter religius yang dicontohkan oleh guru dalam pembelajaran yaitu

\begin{tabular}{ll}
\hline 14 & Linge. \\
15 & Ahmadi and Utami. \\
16 & Young.
\end{tabular}


memulai dan mengakhiri pembelajaran dengan doa, menyampaikan pembelajaran dengan bahasa santun, berperilaku sopan, mengajarkan kejujuran, peduli sesama, dan lain sebagainya. Sedangkan secara pribadi guru memberi contoh seperti, kedisplinan beribadah, ketertiban pakaian seragam, budaya senyum, salam, sapa, dan lain sebagainya. Sedangkan, contoh teladan yang berkaitan dengan karakter nasionalis seperti, mengikuti upacara bendera dengan khidmat, menyanyikan lagu nasional, memperingati hari Kemerdekaan, hari Pahlawan, dan peringatan hari-hari nasional lainnya. ${ }^{17}$

Bidang non akademik lebih menekankan pada program ekstrakurikuler yang menunjang pembentukan karakter religius dan nasionalis. Program tersebut yaitu Seni Tari, Band Kids, Robotika, Olimpiade MIPA, Klub Bahasa, Marching Band, Seni Beladiri, Teknologi Informatika dan Komputer, Khitobah, Menggambar dan Murotal.

Pengembangan diri di SDM Plus Salatiga adalah kegiatan yang bertujuan memberikan kesempatan kepada peserta didik untuk mengembangkan dan mengekspresikan diri sesuai dengan kebutuhan, bakat, minat peserta didik. Pengembangan bakat yang berkaitan dengan ini seperti Pramuka, Usaha Kesehatan Sekolah dengan program Dokter Cilik, Polisi Cilik, Unit Perpustakaan dan Bimbingan dan Konseling.

SD Muhammadiyah juga melaksanakan program nasionalis dan patriotisme. Beberapa program rutin dan terprogram dalam menanamkan nilai cinta tanah air yaitu, 1) apel pagi menyanyikan lagu kebangsaan dan daerah serta membaca pancasila, 2) upacara bendera setiap hari Senin, dan 17 Muthoifin, 'MODEL PENYELESAIAN KONFLIK ANTAR KELOMPOK', 2015, pp. 96-108.
3) peringatan hari-hari nasional, seperti, peringatan hari Kemerdekaan RI, hari Pahlawan, hari Kartini, hari Kebangkitan Pancasila dan hari Pendidikan Nasional. ${ }^{18}$

\section{Sesama manusia}

Program filantropi cilik merupakan salah satu program dalam rangka membantu meringankan beban sesama manusia. Program ini bekerjasama dengan Lazismu dalam pengelolaannya. Kegiatan pembiasaan terprogram yang lain yaitu pesantren ramadhan, bakti sosial, pelaksanaan idul qurban, zakat fitrah, takjil gembira, infaq Jumat dan pelaksanaan manasik haji. Kegiatan spontanitas yaitu, peserta didik secara spontan menyisihkan uang saku untuk membantu korban bencana. Takjil bersama, kegiatan ini biasa dilakukan pada saat bulan ramadhan bersamasama antara guru, wali, dan siswa SD Muhammadiyah Plus Salatiga.

\section{Tuhan.}

Nilai ketaatan menjadi salah satu dasar pelaksanaan program penguatan karakter religius di SDM Plus Salatiga. Program pembiasaan menjadi program unggulan untuk menanamkan pendidikan karakter religius. Program pembiasaan terdiri dari pembiasaan rutin dan terprogram. Pembiasaan rutin meliputi: 1) mengucap salam dan berjabat tangan, 2) sholat dhuha, 3) tadarus Alquran, 4) salat berjamaah dhuhur, 5) gerakan membuang sampah pada tempatnya, 6) gerakan merawat tanaman, 7) berdoa sebelum dan sesudah makan, dan berdoa sebelum dan sesudah belajar. Sedangkan, pembiasaan terprogram meliputi: 1) pesantren ramadhan, 2) bakti sosial, 3) pelaksanaan idul qurban, 4) zakat fitrah, 5) takjil gembira, 6) infaq 18 Sudarno shobron Muthoifin and Suhaimi Ab Rahman, 'Humanist Islam in Indonesia Ahmad Syafii Maarif Perspective', Humanities \& Social Sciences Reviews, 7.6 (2019), 780-86 <https://giapjournals.com/index. php/hssr/article/view/hssr.2019.76118/2384>. 
Jumat dan 7) pelaksanaan manasik haji. Melalui beberapa pembiasaan tersebut nilai ketaatan terhadap Tuhan Yang Maha Esa secarara otomatis telah ditanamkan dan dibiasakan sehingga peserta didik mengetahui informasi yang selanjutnya menerapkan suatu nilai dalam perilaku sehari-hari yaitu perilaku nilai karakter religius, yang mencerminkan keberimanan Tuhan Yang Maha Esa.

\section{Lingkungan.}

SD Muhammadiyah Plus Salatiga merupakan salah satu sekolah swasta Islam yang berada di Kota Salatiga yang selalu membangun good comunication dengan berbagai pihak. Partisipasi lembaga-lembaga negeri maupun swasta dan masyarakat yang ada di sekitar Salatiga dan Jawa Tengah bahkan nasional, seperti kerja sama dengan KODIM Salatiga, bekerjasama dengan Polsek Sidomukti, bekerjasama dengan DPRD Kota Salatiga, DPR RI Pusat Jakarta untuk belajar menjadi dewan/legeslatif, belajar bersama Walikota Salatiga tentang perang eksekutif.

Pada bulan Ramadhan SD Muhammadiyah menggandeng perusahaan-perusahaan seperti Dealer Honda dan Smartfren dalam acara takjil gembira, Bank BTN, Camat, Lurah dan masyarakat sekitar Salatiga dalam acara bakti sosial, DISDIKPORA, UPTD, PUSKESMAS, BAPERMAS, BKK, IAIN, UKSW dan kerja sama-kerja sama lain.

SD Muhammadiyah menerapkan senantiasa aktif dalam kegiatan lingkungan, baik pemerintahan, tingkat kecamatan maupun dilingkugan sekitar. Guru SD Muhammadiyah Plus Salatiga aktif dalam kegiatan pemerintah kota Salatiga misalnya mengikuti peringatan hari besar nasional dan hari besar agama. Menghadiri undangan pemerintah kota. Ikut berpartisipasi dalam lomba guru dan kepala sekolah lolos sebagai juara. Guru berprestasi, guru mata pelajaran, dan perlombaan yang lainnya. Bahkan dapat mewakili Salatiga sebagai kepala sekolah berprestasi tingkat nasional, Sutomo kala itu. Berlanjut dengan Ainul Huri generasinya juga maju kepala berprestasi tingkat propinsi jawa tengah. Berperan aktif dalam forum guru kota Salatiga maupun tingkat nasional.

Siswa-siswi SD Muhammadiyah Plus Salatiga juga tidak ketinggalan dalam kegiatan pemerintahan kota Salatiga. Peringatan hari besar nasional maupun keagamaan. Berprestasi dalam berbagai lomba tingkat kecamatan, kota, propinsi maupun nasional. Sebut saja Wildan kontestan DAI cilik tingkat nasional. Robotika, Pencak Silat, Tahfidz, Azan tingkat nasional dan berbagai perlombaan yang lain dan mampu mengharumkan nama kota Salatiga.

\section{KESIMPULAN}

Sekolah Dasar Muhammadiyah Plus Salatiga bekerjasama dengan Lazismu mengajak siswa untuk ikut membantu sesama. Program yang dilakukan adalah dengan filantropi cilik. Filantropi merupakan program Lazismu yang kemudian disinergikan dengan SD Muhammadiyah Plus Salatiga. Penelitian ini fokus Bermuhammadiyah melalui Spiritual Amal Saleh Filantropi Cilik Lazismu. Hasilnya adalah Direktur, kepala sekolah dan para guru bersinergi mendukung dan memberikan suport kepada siswa terhadap filantropi cilik Lazismu ini. Sementara siswa juga menyambut dengan baik pelaksanaan filantropi ini, bahkan mendapat dukungan pula dari orang tua mereka. Penelitian ini juga berjalan dengan efektif dan optimal sesuai dengan penelitian yang dilakukan oleh Linge dan Makhrus \& Utami. Dalam uraiannya, penelitian ini menggunakan teori dari Dyson bahwa spiritual berhubungan dengan tiga faktor spiritualitas yaitu diri sendiri,sesama, Tuhan, dan lingkungan. 


\section{DAFTAR PUSTAKA}

Abidin, Zaenal, 'Manifestasi Dan Latensi Lembaga Filantropi Islam Dalam Praktik Pemberdayaan Masyarakat: Suatu Studi Di Rumah Zakat Kota Malang', Jurnal Studi Masyarakat Islam, 15 (2012), 197-214

Ahmadi, Makhrus, and Restu Frida Utami, 'Peran Filantropi Islam Dalam Pemberdayaan Masyarakat Di Kabupaten Banyumas', in Seminar Nasional Hasil-Hasil Penelitian Dan Pengabdian LPPM Universitas Muhammadiyah Purwokerto, 2017

Amir, Yulmaida, and Diah Rini Lesmawati, 'Religiusitas Dan Spiritualitas: Konsep Yang Sama Atau Berbeda?', Jurnal Ilmiah Penelitian Psikologi, 2.2 (2016), 67-73

Hasyim, Fuad, 'Gerakan Filantropi Islam Di Amerika', Jurnal Studi Al-Qur'an, 14.1 (2018), 16-31

Hidayati, Okta Nurul, 'Filantropi Dakwah Dan Kaum Minoritas Di Indonesia', Academika, 1.2 (2017)

Jusuf, Chusnan, 'Filantropi Modern Untuk Pembangunan Sosial', Jurnal Penelitian Dan Pengembangan Kesejahteraan Sosial, 12.1 (2007), 74-84

Linge, Abdiyansyah, 'Filantropi Islam Sebagai Instrumen Keadilan Ekonomi', Jurnal Perspektif Ekonomi Darussalam, 1.September (2015), 154-71

Muthoifin, 'Model Penyelesaian Konflik Antar Kelompok', 2015, Pp. 96-108

Muthoifin, and Nuha, 'The Optimization of Local Autonomy Politic for Nation Progress and Synergetic on Islamic Perspective', in The 4th University Research Coloquium 2016, 2016, pp. 72-79 <https://publikasiilmiah.ums.ac.id/xmlui/ handle/11617/7679>

Muthoifin, Sudarno shobron, and Suhaimi Ab Rahman, 'Humanist Islam in Indonesia Ahmad Syafii Maarif Perspective', Humanities $\mathcal{E}$ Social Sciences Reviews, 7.6 (2019), 780-86 <https://giapjournals.com/index.php/hssr/article/view/ hssr.2019.76118/2384>

Saepudin, Dindin Moh, M Solahudin, Izzah Faizah, and Siti Rusydati, 'Iman Dan Amal Saleh Dalam Al Quran (Studi Kajian Sematik)', Al Bayan: Jurnal Studi Al Quran Dan Tafsir, 1.Juni (2017), 10-20

Sya'roni, Moch. Hasan, 'Implementasi Kegiatan Amal Saleh Dalam Peningkatan Kecerdasan Spiritual : Studi Kasus Di Pondok Pesantren Al Urwatul Wutsqo Bulurejo Diwek Jombang', Didaktika Religi, 2.1 (2014), 65-90

Tamin, I. H., 'Peran Filantropi Dalam Pengentasan Kemiskinan Di Dalam Komunitas Lokal.', Jurnal Sosiologi Islam, 1.1 (2011), 36

Young, Koopsen., Spiritual, Kesehatan, Dan Penyembuhan (Medan: Bina Media Perintis, 2007)

Yusran, 'Amal Saleh : Doktrin Teologi Dan Sikap Sosial', Al-Adyan, 1.Desember 2015 (2004) 